\title{
3.04
}

\section{Diálogos para efetivação do Sistema Único de Saúde de Minas Gerais}

\author{
Dialogues for realization of the National Health System of Minas Gerais
}

\section{Ludmylla Souza de Oliveira Silva Dayrell}

Advogada. Especialista em Direito Sanitário. Assessora Jurídica da Secretaria de Estado de Saúde/MG, Belo Horizonte, Minas Gerais, Brasil.

\author{
Aline Fernanda da Silva Araújo \\ Advogada. Especialista em Direito Público. Assessora na Assessoria Técnica da \\ Secretaria Estadual de Saúde/MG, Belo Horizonte, Minas Gerais, Brasil.

\section{Vânia Faerman Rabello} \\ Advogada. Assessora Chefe na Assessoria Técnica da Secretaria Estadual de \\ Saúde/MG, Belo Horizonte, Minas Gerais, Brasil.
}

Resumo: Desde a promulgação da Constituição de 1988, a saúde é tratada como direito fundamental que deve ser instituído através de políticas públicas. Entretanto, não deixa de ser um direito subjetivo público, que permite ao cidadão o seu pleito, inclusive pela via judicial, quando as políticas públicas implementadas em sua região não forem suficientes. O fenômeno Judicialização vem crescendo de forma exponencial no Brasil. Minas Gerais já sofre com os impactos financeiros causados e procura minimizar os efeitos negativos dessa demanda crescente, principalmente no que diz respeito aos atrasos no cumprimento de ações que geram o desgaste do cidadão e, até mesmo, a incidência de multas por demora no cumprimento. Com base nesta premissa, foram realizados vários diálogos entre a Secretaria de Saúde do Estado de Minas Gerais, o Ministério Público e o Poder Judiciário dos quais resultou uma proposta de mudança na estrutura dos órgãos de atendimento que busca responder de forma mais eficaz e eficiente as demandas judiciais.

Palavras-chave: Judicialização da Saúde; justiça e saúde; SUS.

Key-words: Judicialization of health; justice and health; SUS.

\section{Introdução}

Com a promulgação da Constituição Federal em 1988, a saúde passou a ter o caráter de direito fundamental protegido e garantido pela Carta Magna, e, desde então, o Estado realiza, conforme determinação constitucional, politicas sociais e econômicas visando garantir o direito à saúde para todos, com acesso universal e igualitário às ações e serviços para sua promoção, proteção e recuperação. 
A própria Constituição Federal (arts. 196 e 30, VII) preconizou os princípios e as diretrizes do Sistema Único de Saúde (SUS), que foram reforçados pela Lei Orgânica do SUS (Lei $n^{\circ}$ 8.080, de 19 de setembro de 1990), editada em 1990, bem como pela constante evolução da legislação sanitária, através das Normas Operacionais Básicas, Normas Operacionais da Assistência à Saúde, Pacto pela Saúde e, mais recentemente, o Contrato Organizativo da Ação Pública de Saúde - COAP.

Toda a citada legislação procurou fortalecer as diretrizes do SUS, como: ações e serviços públicos de saúde integrantes de uma rede regionalizada e hierarquizada; execução descentralizada para o nível local, com direção única em cada esfera de governo; integralidade do atendimento, com prioridade para as atividades preventivas, sem prejuízo dos serviços assistenciais; e participação da comunidade.

Apesar dessa evolução, em razão de diversos fatores, tais como: falta de definição clara sobre a extensão da integralidade das ações de saúde, ineficiência na assistência e, até mesmo, falta de medicamentos, o fenômeno da "judicialização da saúde" cresceu de forma exponencial nos últimos anos. Assim, cada vez mais, o poder judiciário é instado a decidir sobre o direito do indivíduo ou da coletividade que alega não ter acesso a procedimentos, exames, insumos ou medicamentos.

Em muitos casos, a decisão preliminar do Poder Judiciário, favorável ao pleito, é exarada somente com base na manifestação do autor da ação, contribuindo para a proliferação de ações judiciais individuais que podem comprometer o financiamento de programas de saúde e a garantia da assistência da coletividade.

Com base em constantes discussões acerca do tema Judicialização a Secretaria de Saúde do Estado de Minas Gerais (SES/MG) vem construindo diversas parcerias com o Poder Judiciário e com o Ministério Público, na busca pela efetivação dos direitos do cidadão.

Neste trabalho, destacaremos a evolução desses diálogos e os projetos, frutos dessas discussões.

O primeiro, em observância à Recomendação $n^{\circ} 31$ do Conselho Nacional de Justiça (CNJ), de 30 de março de 2010, que orienta os tribunais a celebrarem convênios que visem à obtenção de apoio técnico para auxílio dos magistrados na formação de juízo de valor na apreciação de demandas relativas à saúde, e o segundo, idealizado a partir do voto exarado pelo Conselheiro Ney José de Freitas, aos 04 de abril de 2013, sugerindo ao CNJ a edição de recomendação para a especialização de 
varas da fazenda pública para processar e julgar ações que tenham por objetivo o direito à saúde e para a priorização de julgamentos dos processos relativos a demandas de saúde complementar. ${ }^{1}$

\section{Histórico das ações judiciais no Estado de Minas Gerais}

O direito à saúde como direito fundamental do cidadão foi inserido no sistema brasileiro através da Constituição de 1988, mas sua requisição como direito subjetivo público é um fenômeno recente, de pouco mais de uma década.

Apesar de recente, a judicialização vem causando um grande impacto nas políticas públicas de saúde com seus crescentes gastos.

Os Gráficos 1 e 2 demonstram a evolução da demanda e dos gastos com as ações de saúde no Estado de Minas Gerais, nos últimos quatro anos.

Gráfico 1 - Ações judiciais no Estado de Minas Gerais segundo o ano.

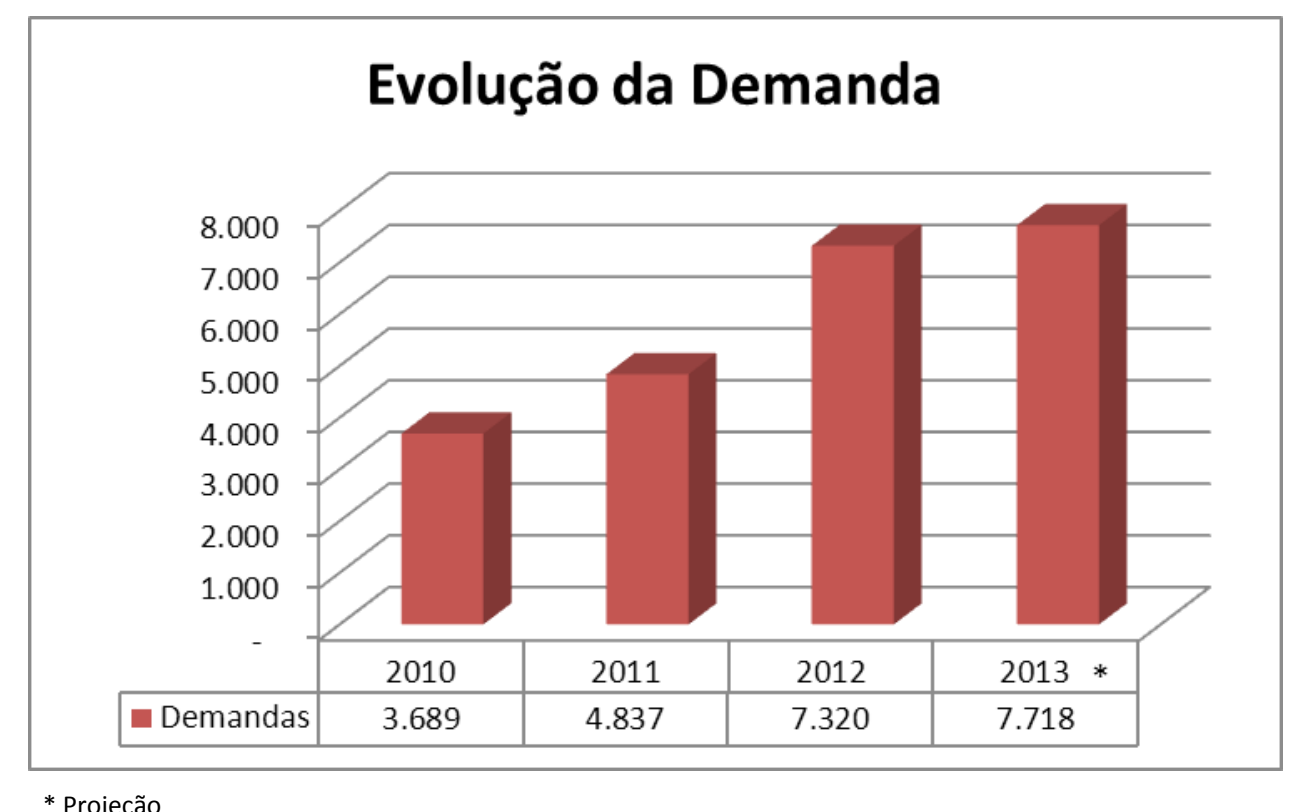

Fonte: Assessoria Técnica da Secretaria de Estado de Saúde de Minas Gerais.

\footnotetext{
${ }^{1}$ Voto exarado aos 04/04/2013 no Pedido de Providências protocolado por Flávio Dino de Castro e Costa, através do $\mathrm{n}^{\circ}$ 0002150-61.2012.2.00.0000, disponível no sítio eletrônico: http://www.migalhas.com.br/arquivo_artigo/art20130807-07.pdf
} 
Gráfico 2 - Gasto (R\$ 1,00) com ações de saúde no Estado de Minas Gerais, segundo o ano.

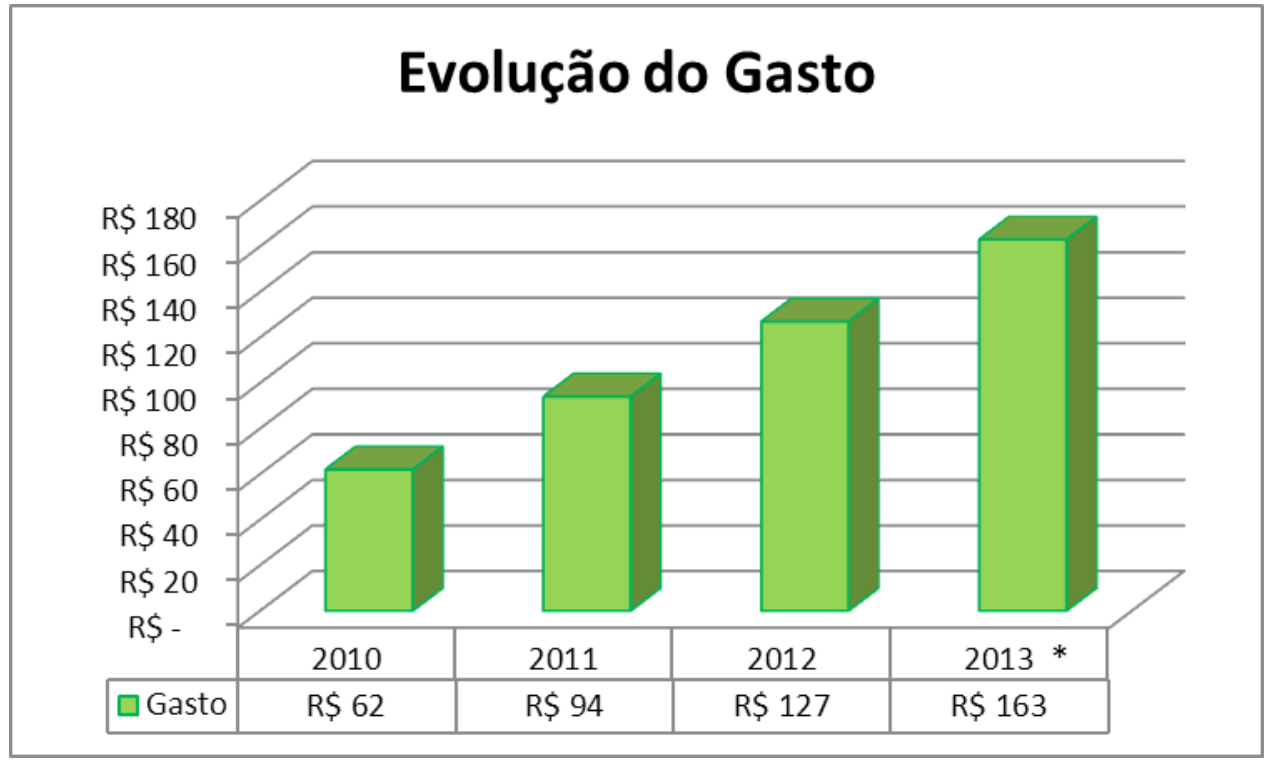

*Projeção

Fonte: Sistema Integrado de Administração Financeira de Minas Gerais - SIAF/MG.

Esse crescimento do número de ações obrigou o Governo de Minas Gerais, por meio da Secretaria de Estado de Saúde, a tomar várias medidas na busca pela melhoria e diminuição do tempo de atendimento às ações judiciais.

A primeira medida, em meados de 2007, foi a criação, no âmbito da Assessoria Jurídica da SES/MG, do Núcleo de Suporte à Judicialização da Saúde, com competências exclusivas para o recebimento da ordem judicial, elaboração do pedido de compras e acompanhamento de todo o procedimento interno até o atendimento integral à ação, o que inclui a dispensação dos medicamentos ou insumos ao paciente.

Com a demanda crescente, o Núcleo tomou status de Superintendência e passou a ser denominado 'Assessoria Técnica', possuindo mais independência e exclusividade para o cumprimento de suas competências.

Diante de maior dedicação e aprofundamento aos casos, foi constatada a dificuldade em lidar com a grande diversidade de pedidos, sendo necessária a instituição de parcerias internas com a Superintendência de Assistência Farmacêutica e a Superintendência de Atenção à Saúde.

Dessa necessidade surgiu também o primeiro projeto para melhoria das respostas da SES/MG aos pleitos judiciais: o Centro Colaborador do Sistema Único 
de Saúde de Minas Gerais (SUS/MG) para estudos farmacológicos e epidemiológicos.

O citado Centro consiste numa parceria com a Fundação de Desenvolvimento da Pesquisa da Universidade Federal de Minas Gerais (FUNDEP/UFMG) e parte do pressuposto de que cada configuração tecnológica cria novas realidades econômicas, sociais e culturais, mas que seria uma grande ameaça à integridade dos sistemas de saúde a incorporação tecnológica automática, sem a devida análise crítica de benefícios, custos e interesses alheios ao bem estar coletivo (Andrade, 2008).

Essa parceria visava, entre outras premissas, a cooperação entre acadêmicos e profissionais para a produção de informações que subsidiassem o adequado planejamento estratégico na área da saúde e de avaliações sobre o uso de medicamentos selecionados, numa forma de levar a informação adequada ao Judiciário e tentar reduzir as inconformidades encontradas em certas decisões.

A parceria rendeu muitos frutos, mas ainda não era suficiente para impactar no crescimento do fenômeno Judicialização. Era preciso mais imparcialidade nas notas técnicas para que os juízes a tratassem como uma construção científica e não como uma peça de defesa do Poder Executivo, na incessante busca por diminuir os gastos com as decisões judiciais individuais.

A inspiração veio com a promulgação da Recomendação $n^{\circ} 31$, de 30 de março de $2010^{2}$, onde o CNJ recomenda aos tribunais a adoção de medidas visando a melhor subsidiar os magistrados e demais operadores do Direito, de forma a assegurar maior eficiência na solução das demandas judiciais envolvendo a assistência à saúde.

Em 2012, baseados na publicação da citada Recomendação, foi assinado um Termo de Cooperação Técnica entre a SESMG e o Tribunal de Justiça do Estado de Minas Gerais (TJMG), visando o oferecimento de subsídios técnicos aos magistrados, exclusivamente por correspondência eletrônica, nas ações que tenham por objeto compelir o Estado de Minas Gerais e os municípios ao fornecimento de medicamentos, insumos para a saúde, exames diagnósticos, tratamentos médicos e insumos nutricionais.

Entre as competências da SESMG estavam a disponibilização de técnicos da área da saúde para auxiliar os magistrados na análise das ações, arcando, inclusive, com as despesas para esse fim. Por sua vez, o Tribunal se comprometeu a prestar

2 Inteiro Teor disponível no sítio eletrônico: http://www.cnj.jus.br/atos-administrativos/atos-dapresidencia/322-recomendacoes-do-conselho/12113-recomendacao-no-31-de-30-de-marco-de-2010 . 
informações e esclarecimentos, por meio de relatórios mensais, ao acompanhamento e controle da execução do objeto do termo de cooperação, bem como ao cumprimento dos prazos estabelecidos aos técnicos da área da saúde na confecção de pareceres.

Para cumprimento do disposto no termo de cooperação técnica, a SESMG buscou a imparcialidade ao contratar a equipe do Núcleo de Avaliação de Tecnologias (NATS), vinculado ao Hospital das Clínicas da Universidade Federal de Minas Gerais, para dar a assistência pretendida aos juízes.

Entretanto, após um ano de contrato, o percentual de utilização das notas técnicas para embasamento das decisões encontra-se em torno de $21 \%$, ou seja, em um universo de 38 processos que utilizaram o NATS para emitir decisão, entre os meses de abril e julho de 2013, apenas 8 tiveram sua decisão modificada com fundamento em notas técnico-científicas.

Essa realidade transmite a ideia de um diálogo ainda muito distante, que não reflete a sintonia existente entre os Poderes, ou mesmo o Ministério Público, na tentativa de resolução de conflitos, tamanha a complexidade do tema judicialização, restando necessária a adoção de medidas interdisciplinares e intersetoriais mais efetivas e presentes para o atingimento dos resultados esperados, conforme nos sugere o Conselheiro Ney José de Freitas no voto exarado aos 04/04/13, nos autos do pedido de providências $n^{\circ}$ 0002150-61.2012.2.00.0000.

\section{A nova proposta da Secretaria de Estado de Saúde de Minas Gerais}

Como mais recente alternativa na busca de resolução de conflitos de judicialização, a SES/MG vem trabalhando num projeto de reestruturação do núcleo de atendimento às demandas judiciais e recentemente teve o apoio do Ministério Público e do Tribunal de Justiça do Estado de Minas Gerais na proposta de junção de todos os setores envolvidos no processo de atendimento às decisões judiciais e requerimentos do órgão ministerial.

O Núcleo de Atendimento à Judicialização da Saúde teria caráter intersetorial, sendo composto por todos os órgãos, internos e externos, envolvidos na execução das demandas e se responsabilizando pelas questões administrativas e jurídicas do processo, através das seguintes competências:

- $\quad$ representação do Estado junto ao Poder Judiciário; 
- $\quad$ recebimento e assinatura de intimações e citações judiciais e de requerimentos do Ministério Público;

- $\quad$ formalização de procedimentos licitatórios e gerenciamento de Atas de Registro de Preços e Contratos, incluindo possíveis processos de penalização a fornecedores.

Atualmente, os processos judiciais dão entrada no Poder Executivo do Estado de Minas Gerais pela Advocacia Geral do Estado (AGE) e sua execução passa pelos seguinte setores da SES/MG:

1 - Assessoria Técnica;

2 - Diretoria de Compras;

3 - Assessoria Jurídica;

4 - Auditoria Setorial (nos casos de dispensa e inexigibilidade de licitação);

5 - Superintendência de Planejamento e Finanças,

6 - Diretoria de Contratos,

7-Almoxarifado e,

8 - Farmácia de dispensação.

A proposta é reunir, num único endereço, todas as etapas do processo de atendimento, com representantes de todos os setores acima citados. Pretende-se dar ao Núcleo o status de Subsecretaria e a responsabilidade por todo o processo que envolve os seguintes procedimentos (Gráfico 3).

Gráfico 3 - Atividades do Núcleo de Atendimento à Judicialização da Saúde

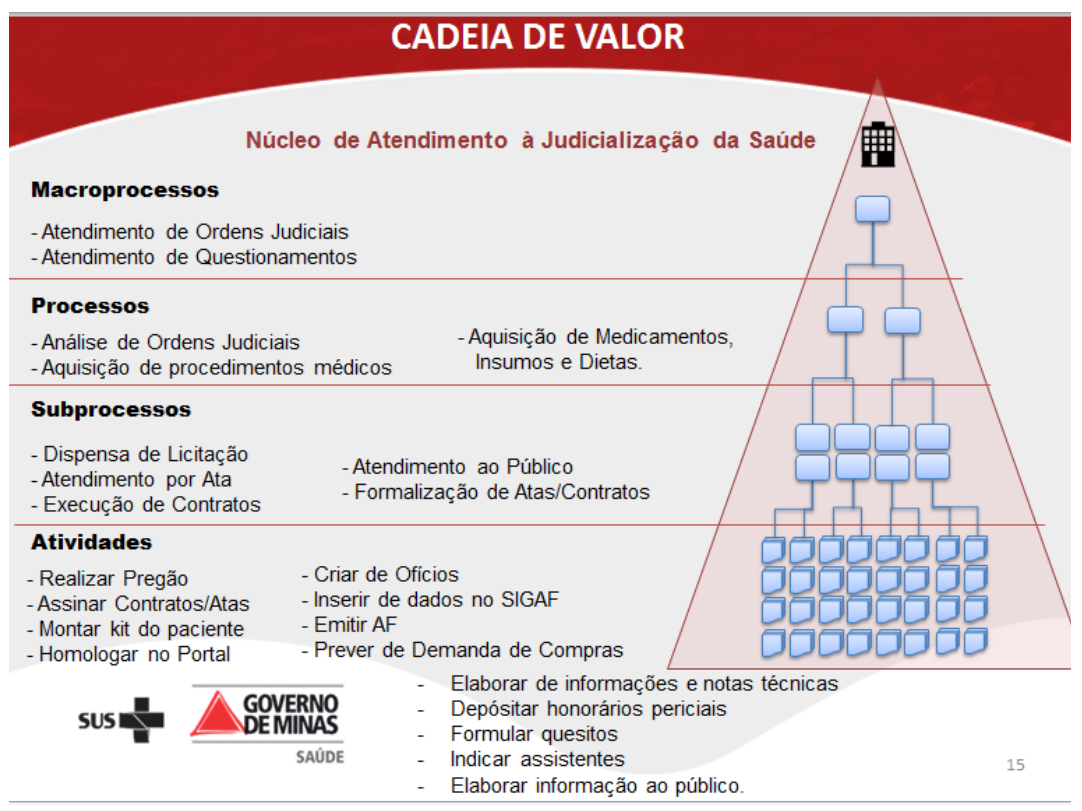


A junção de todas as etapas em um único local permite que os órgãos envolvidos no processo tenham mais autonomia e adotem uma linguagem única, possibilitando tornar mais célere o processo de aquisição de medicamentos, insumos ou procedimentos médicos e mais eficiente o atendimento ao cidadão, na medida em que extingue fluxos burocráticos que agregavam dias à ação.

Além do núcleo central, que pretende se instalar ainda durante o ano de 2013, o Núcleo de Atendimento à Judicialização da Saúde pretende contar com equipes presentes nas 28 regionais de saúde, compostas por, no mínimo, um médico, um enfermeiro e um Procurador do Estado ou Assessor Jurídico, com atribuições de assessoramento ao juízo e promover tentativas de acordo pela via administrativa.

O Núcleo também prevê, em continuidade à postura já assumida pela SES/MG, a parceria com as instituições de ensino e pesquisa para capacitação dos agentes envolvidos no processo de judicialização.

Os diálogos entre a SES/MG, o Poder Judiciário e Ministério Público também almejam, num futuro próximo, o cumprimento da Recomendação do CNJ, com a criação de Varas Especializadas de Saúde no Estado de Minas Gerais, de forma a tornar o trabalho mais pautado na realidade do SUS e mais efetivo o atendimento aos pedidos do cidadão.

\section{Conclusão}

A evolução dos núcleos e das parcerias da Secretaria de Estado de Saúde na busca pelo atendimento à Judicialização fica evidente quando nos dispomos a fazer esse resgate histórico.

A ideia de junção de todos os órgãos envolvidos surge após várias tentativas de aperfeiçoamento dos trabalhos realizados pela SES nos processos de atendimento a demandas judiciais.

Prevendo uma maior interação dos órgãos envolvidos, a nova estrutura proposta pela SESMG tornará mais ágil o atendimento às demandas judiciais e reduzirá os custos envolvidos no processo de aquisição e dispensação do medicamento ou insumo, otimizando o gasto de recursos públicos.

A especialização é uma exigência em todos os seguimentos da sociedade e do mercado e decorre de forma natural, fruto de adaptações feitas à medida que evoluímos e alteramos nossos anseios como cidadãos. 
Os diálogos traçados entre a Secretaria de Estado de Saúde, o Poder Judiciário e o Ministério Público sempre foram benéficos para o fortalecimento das políticas públicas e sempre buscaram contribuir para um retorno mais eficiente para o cidadão, em todos os aspectos.

Uma nova estrutura, nos moldes propostos pela SES/MG, reduzirá o tempo de atendimento às demandas judiciais e ministeriais e contribuirá para a otimização dos gastos públicos.

O Núcleo de Atendimento à Judicialização da Saúde terá mais autonomia e controle total dos procedimentos internos, poderá gerenciar de forma mais efetiva os estoques de insumos e medicamentos e conseguirá respostas mais ágeis a defensores públicos, promotores de justiça, juízes e desembargadores, além, é claro, do retorno mais célere e eficaz ao cidadão.

\section{Referências}

BRASIL. Constituição Federal Brasileira de 1988. Diário Oficial [da República Federativa do Brasil], Brasília, 5 de outubro de 1988.

DI PIETRO, Maria Sylvia Zanella. Parcerias na Administração Pública (4 ed.). São Paulo: Ed. Atlas, 2002.

BRASIL. Lei Federal $n^{\circ} 8.080$, de 19 de setembro de 1990. Dispõe sobre as condições para a promoção, proteção e recuperação da saúde, a organização e o funcionamento dos serviços correspondentes e dá outras providências. Diário Oficial [da República Federativa do Brasil], Brasília, 20 de setembro de 1990.

BRASIL. Lei Federal $\mathrm{n}^{\circ}$ 8.142, de 28 de setembro de 1990. Dispõe sobre a participação da comunidade na gestão do Sistema Único de Saúde (SUS) e sobre as transferências intergovernamentais de recursos financeiros na área da saúde e dá outras providências. Diário Oficial [da República Federativa do Brasil], Brasília, 29 de setembro de 1990.

SILVA, José Afonso da. Curso de Direito Constitucional Positivo (18 ed.). São Paulo: Ed. Malheiros Editores, 2000.

Sítio eletrônico do Conselho Nacional de Justiça - CNJ: www.cnj.jus.br 